\title{
Hydroxymethanesulfonic acid in size-segregated aerosol particles at nine sites in Germany
}

\author{
S. Scheinhardt, D. van Pinxteren, K. Müller, G. Spindler, and H. Herrmann \\ Leibniz-Institut für Troposphärenforschung (TROPOS), Permoserstraße 15, 04318 Leipzig, Germany \\ Correspondence to: H. Herrmann (herrmann@tropos.de)
}

Received: 22 November 2013 - Published in Atmos. Chem. Phys. Discuss.: 10 December 2013

Revised: 17 March 2014 - Accepted: 19 March 2014 - Published: 7 May 2014

\begin{abstract}
In the course of two field campaigns, sizesegregated particle samples were collected at nine sites in Germany, including traffic, urban, rural, marine and mountain sites. During the chemical characterisation of the samples some of them were found to contain an unknown substance that was later identified as hydroxymethanesulfonic acid (HMSA). HMSA is known to be formed during the reaction of $\mathrm{S}(\mathrm{IV})\left(\mathrm{HSO}_{3}^{-}\right.$or $\mathrm{SO}_{3}^{2-}$ ) with formaldehyde in the aqueous phase. Due to its stability, HMSA can act as a reservoir species for $\mathrm{S}(\mathrm{IV})$ in the atmosphere and is therefore of interest for the understanding of atmospheric sulfur chemistry. However, no HMSA data are available for atmospheric particles from central Europe, and even on a worldwide scale data are scarce. Thus, the present study now provides a representative data set with detailed information on HMSA concentrations in size-segregated central European aerosol particles. HMSA mass concentrations in this data set were highly variable: HMSA was found in 224 out of 738 samples $(30 \%)$, sometimes in high mass concentrations exceeding those of oxalic acid. On average over all $154 \mathrm{im}$ pactor runs, $31.5 \mathrm{ng} \mathrm{m}^{-3}$ HMSA was found in $\mathrm{PM}_{10}$, contributing $0.21 \%$ to the total mass. The results show that the particle diameter, the sampling location, the sampling season and the air mass origin impact the HMSA mass concentration. Highest concentrations were found in the particle fraction $0.42-1.2 \mu \mathrm{m}$, at urban sites, in winter and with eastern (continental) air masses, respectively. The results suggest that HMSA is formed during aging of pollution plumes. A positive correlation of HMSA with sulfate, oxalate and PM is found $\left(R^{2}>0.4\right)$. The results furthermore suggest that the fraction of HMSA in PM slightly decreases with increasing $\mathrm{pH}$.
\end{abstract}

\section{Introduction}

In the course of two field campaigns (REGKLAM and GUAN, see Scheinhardt et al., 2013a, and Birmili et al., 2009), numerous size-segregated particle samples were collected at nine sites in Germany. During the chemical characterisation of the samples a fraction of the samples were found to contain hydroxymethanesulfonic acid (HMSA, $\mathrm{HO}-\mathrm{CH}_{2}-$ $\left.\mathrm{SO}_{3} \mathrm{H}\right)$.

HMSA and other hydroxyalkanesulfonic acids (HASA; $\mathrm{HO}-\mathrm{CHR}-\mathrm{SO}_{3} \mathrm{H}$ with $\left.\mathrm{R}=-\left(\mathrm{CH}_{2}\right)_{n} \mathrm{H}\right)$ were suggested to be involved in atmospheric sulfur chemistry, notably regarding sulfate formation. Sulfate is one of the main constituents of atmospheric aerosol particles. It is mainly formed from the oxidation of $\mathrm{S}(\mathrm{IV})$ by $\mathrm{H}_{2} \mathrm{O}_{2}$ in the atmospheric aqueous phase and especially in cloud droplets. Dissolved S(IV) originates from gaseous $\mathrm{SO}_{2}$, which, in central Europe, is mainly emitted by human activities, e.g. coal burning. $\mathrm{SO}_{2}$ dissolution is described by a Henry's law equilibrium, followed by the formation of hydrogen sulfite $\left(\mathrm{HSO}_{3}^{-}\right.$) or sulfite $\left(\mathrm{SO}_{3}^{2-}\right)$. However, in various field studies, it has been observed that $\mathrm{S}(\mathrm{IV})$ concentrations in the atmospheric aqueous phase were often higher than expected from Henry's law (Richards et al., 1983; Munger et al., 1984). Rapidly, the reaction of dissolved $\mathrm{SO}_{2} / \mathrm{HSO}_{3}^{-} / \mathrm{SO}_{3}^{2-}$ with dissolved aldehydes, yielding hydroxyalkanesulfonic acids, was identified as an explanation for this observation (Munger et al., 1984). Hydroxymethanesulfonic acid turned out to be the most important HASA since formaldehyde, its organic precursor, is the most common aldehyde in the atmospheric aqueous phase (Olson and Hoffmann, 1989; Takeuchi et al., 2001). 


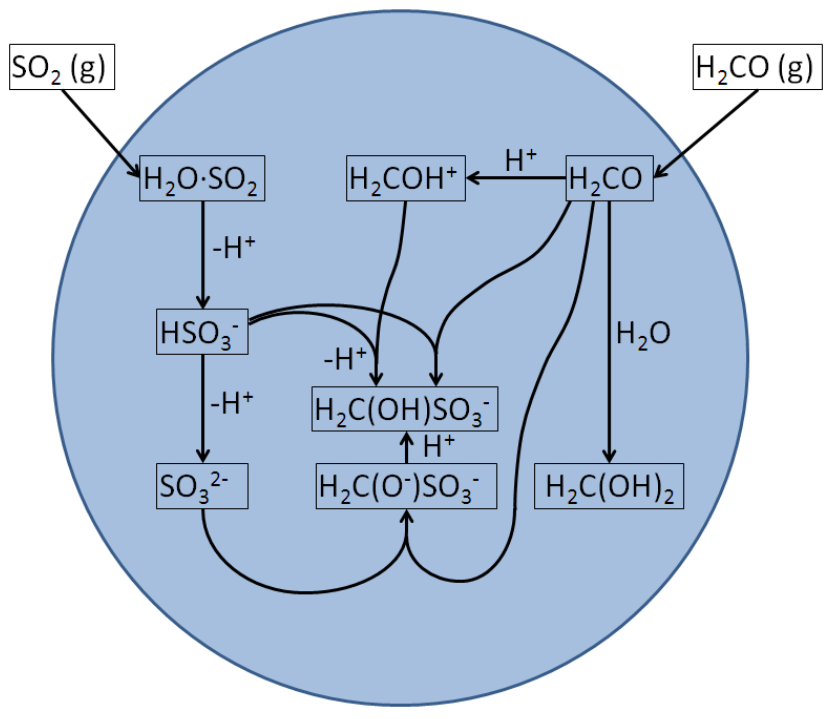

Fig. 1. Formation pathways of HMSA (Munger et al., 1984; Olson and Hoffmann, 1989). All reactions are equilibrium reactions. The circle indicates an atmospheric droplet.

An overview of the HMSA formation mechanism is given in Fig. 1. HMSA formation is most rapid at $\mathrm{pH}>5$, but HMSA decomposition as well is enhanced at higher $\mathrm{pH}$. The highest stability is thus observed at acidic $\mathrm{pH}$ (Sorensen and Andersen, 1970; Munger et al., 1986). HMSA is comparably stable and not readily oxidised (Hoigné et al., 1985; Martin et al., 1989; Ojo et al., 2004). It therefore accumulates in the atmosphere and can be found in high concentrations. Katagiri et al. (1996) found hydroxymethanesulfonate to be the third most important anion in dew samples collected in Japan. It has been suggested that the high HMSA concentrations may act as a reservoir species for atmospheric S(IV) (Richards et al., 1983; Munger et al., 1984 and 1986; Voisin et al., 2000) and might thus impact S(IV) oxidation kinetics (McArdle and Hoffmann, 1983) by shielding S(IV) from the direct oxidation by non-radical oxidants such as $\mathrm{H}_{2} \mathrm{O}_{2}$.

The HMSA data set obtained here was evaluated because HMSA, on the one hand, is of great interest for the understanding of S(IV) oxidation processes but, on the other hand, has only rarely been quantified in atmospheric particles (Suzuki et al., 2001). The aim of the present study is thus to investigate HMSA concentrations in size-segregated atmospheric aerosol particles at selected sites in central Europe in order to identify the main factors determining HMSA mass concentrations. To this end, the influences of particle diameter, sampling location, sampling season and air mass origin are studied.

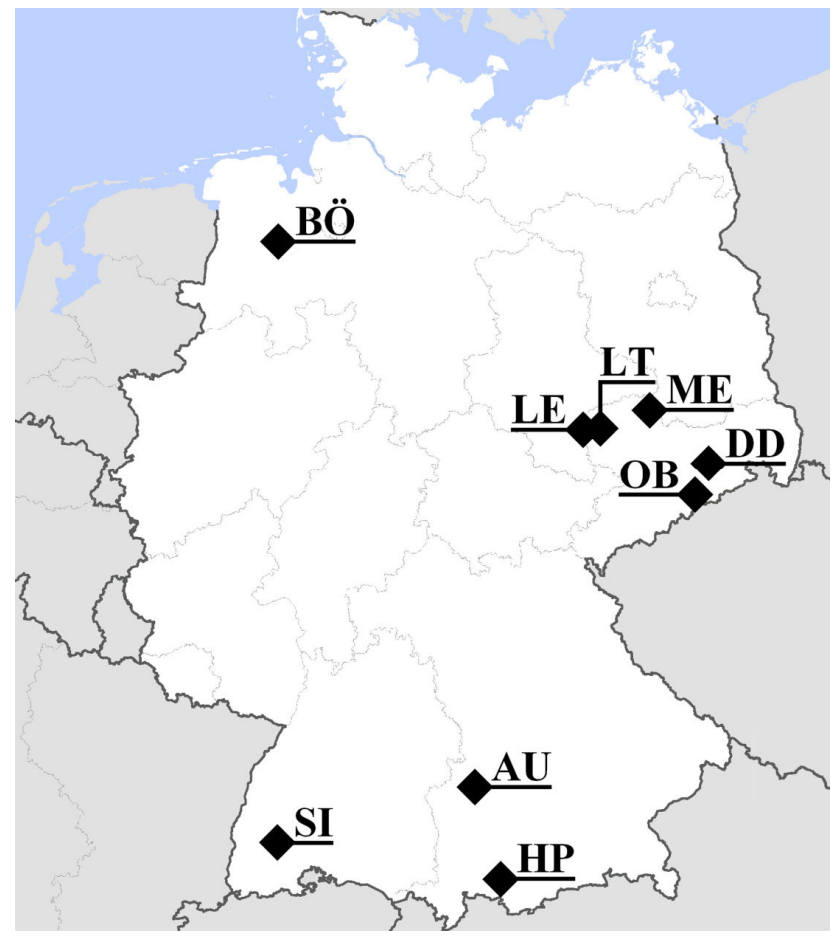

Fig. 2. Sampling sites (see Scheinhardt et al., 2013b). See text for coding explanation.

\section{Material and methods}

\subsection{Particle sampling}

Size-segregated aerosol particle samples were collected in two field campaigns in Germany in 2009 and 2010 as described by Scheinhardt et al. (2013b). Sampling was performed on ring-like aluminium foils using five-stage Berner impactors. Inside the impactors, particles are separated depending on their aerodynamic diameter, the $50 \%$ cut-offs being $0.05-0.14-0.42-1.2-3.5-10 \mu \mathrm{m}$ for impactor stages $1-5$, respectively. Sampling was performed at nine sites in Germany (Fig. 2, see Birmili et al., 2009):

1. Leipzig-Eisenbahnstraße (LE; $51.34^{\circ} \mathrm{N}, 12.37^{\circ} \mathrm{E}$, $119 \mathrm{~m}$ a.s.l.) is a traffic site located about half-way between Leipzig city centre and Leipzig-TROPOS (LT) in a street canyon aligned in the west-east direction. The air inlet is installed about $6 \mathrm{~m}$ above the ground level at the northern side of the canyon.

2. Leipzig-TROPOS (LT; $51.35^{\circ} \mathrm{N}, \quad 12.43^{\circ} \mathrm{E}$, $125 \mathrm{~m}$ a.s.1.) is an urban site located at the roof of TROPOS building, $4 \mathrm{~km}$ northeast of the city centre of Leipzig (530 000 residents). The air inlet is installed $16 \mathrm{~m}$ above the ground level. The site is not directly affected by local particle sources like traffic.

3. Dresden-Winckelmannstraße (DD; $51.04^{\circ} \mathrm{N}$, $13.73^{\circ} \mathrm{E}, 112 \mathrm{~m}$ a.s.1.) is an urban site in the 
city of Dresden (530000 residents). The site is not directly affected by local particle sources like traffic.

4. Augsburg (AU; $48.36^{\circ} \mathrm{N}, 10.91^{\circ} \mathrm{E}, 484 \mathrm{~m}$ a.s.l.) is an urban site located about $1 \mathrm{~km}$ southeast of the city centre of Augsburg (270 000 residents). There are no local particle sources nearby.

5. Melpitz (ME; $51.54^{\circ} \mathrm{N}, 12.93^{\circ} \mathrm{E}, 86 \mathrm{~m}$ a.s.l.) is a well-characterised rural site in the German lowlands (Spindler et al., 2010, 2012, 2013). It is surrounded by meadows.

6. Oberbärenburg $\left(\mathrm{OB} ; 50.78^{\circ} \mathrm{N}, 13.72^{\circ} \mathrm{E}, 735 \mathrm{~m}\right.$ a.s.l. $)$ is a rural site $30 \mathrm{~km}$ south of Dresden. It is located in a low mountain range and is surrounded by forests.

7. Bösel (BÖ; $53.00^{\circ} \mathrm{N}, 7.96^{\circ} \mathrm{E}, 16 \mathrm{~m}$ a.s.l.) is a rural site located $30 \mathrm{~km}$ southwest of Oldenburg (160000 residents), $80 \mathrm{~km}$ south of the North Sea coast.

8. Schauinsland (SI; $47.91^{\circ} \mathrm{N}, 7.91^{\circ} \mathrm{E}, 1205 \mathrm{~m}$ a.s.l.) is a rural site located on the mountain with the same name, around $10 \mathrm{~km}$ southeast of Freiburg im Breisgau (220 000 residents), in the Black Forest.

9. Hohenpeißenberg (HP; $47.80^{\circ} \mathrm{N}, \quad 11.00^{\circ} \mathrm{E}$, $988 \mathrm{~m}$ a.s.1.) is a rural site located $50 \mathrm{~km}$ south of Munich on top of a hill that rises about $300 \mathrm{~m}$ above the surrounding landscape.

Sampling was started whenever the weather forecast predicted favourable meteorological conditions (i.e. no precipitation and a constant air mass origin throughout the sampling day). The sampling period was $24 \mathrm{~h}$, corresponding to a sampled air volume of $108 \mathrm{~m}^{3}$.

Prior to use, the aluminium foils were pre-heated at $300^{\circ} \mathrm{C}$ for at least 2 hours in order to remove organic traces. After sampling, the foils were stored at $-21{ }^{\circ} \mathrm{C}$ until analysis.

\subsection{Classification of sampling days}

Out of the complete data set, only sampling days with unambiguous air mass origins were selected and chemically analysed. This was the case for 30 sampling days, corresponding to 156 impactor runs or 738 Berner impactor foils. Depending on the season and the air mass origin during sampling, sampling days were classified into six categories: Winter West (WiW), Winter North (WiN), Winter East (WiE), Summer West (SuW), Summer North (SuN), and Summer East (SuE). This empirical categorisation has proven to be successful in former studies in central Europe (Spindler et al., 2010, 2012, 2013) and considers differences in PM mass concentrations and compositions under different meteorological conditions. Summer included sampling days between May and October and winter included days between November and April. The air mass origin was determined using 96-hour-backward trajectories from the NOAA HYSPLIT transport model (Hybrid Single Particle Lagrangian Integrated Trajectory Model; Draxler and Hess, 1998; http://ready.arl.noaa.gov/HYSPLIT.php). Backward trajectories were calculated for each sampling day and each sampling site at 10:00 CET and 18:00 CET for arrival heights of 200, 500 and $1000 \mathrm{~m}$ above the ground level. An overview of the sampling events is given in the Supplementary Material.

\subsection{Weighing and chemical analysis}

The determination of the collected particle mass was done gravimetrically using a microbalance (UMT-2, MettlerToledo, Switzerland) after at least $48 \mathrm{~h}$ of equilibration at $(20 \pm 1){ }^{\circ} \mathrm{C}$ and a relative humidity of $(50 \pm 5) \%$. After weighing, the foils were cut with ceramic scissors and chemically analysed.

Chemical analysis was performed after extraction of an aliquot of an aluminium foil in $2 \mathrm{ml}$ of deionised water $(>18 \mathrm{M} \Omega \mathrm{cm})$ following a standard protocol $(10 \mathrm{~min}$ shak ing, 10 min ultrasonic treatment, 10 min shaking). After extraction, the solution was filtered using syringe filters with a pore size of $0.45 \mu \mathrm{m}$.

Main inorganic ions (chloride, nitrate, sulfate) were determined from the aqueous extracts using ion chromatography with conductivity detection (ICS3000, Dionex). Cations were separated applying a methylsulfonic acid eluent and a CS16 (3 mm) column, anions were separated applying a $\mathrm{KOH}$ eluent in a AS18 (2 mm) column. Calibration was done daily, using a four-point standard (Fluka, Switzerland).

HMSA and oxalate were determined from the aqueous extracts using a capillary electrophoresis method described by Kramberger-Kaplan (2003) and Scheinhardt et al. (2013b). In brief, a background electrolyte consisting of $2 \mathrm{mM} 5$ sulfosalicylic acid, $8 \mathrm{mM}$ tris(hydroxymethyl)aminomethane and $0.001 \%$ hexadimethrine bromide at a $\mathrm{pH}$ of 8.2 was used in an Agilent 7100 capillary electrophoresis system. An uncoated fused-silica capillary with an inner diameter of $75 \mu \mathrm{m}$ and a total length of $80.5 \mathrm{~cm}(72 \mathrm{~cm}$ to the detector) was used. The capillary was maintained at $20{ }^{\circ} \mathrm{C}$. Separation of HMSA from other compounds was reached within $13 \mathrm{~min}$, applying a voltage of $-30 \mathrm{kV}$ (corresponding to a current of about $-5 \mu \mathrm{A}$ ) following hydrodynamic sample injection with $750 \mathrm{mbars}$ (corresponding to $1 \%$ of the capillary length). Indirect UV detection with a measurement wavelength of $260 \mathrm{~nm}$ (bandwidth: $20 \mathrm{~nm}$ ), a reference wavelength of $208 \mathrm{~nm}$ (bandwidth: $36 \mathrm{~nm}$ ) and a time resolution of $20 \mathrm{~Hz}$ was used for quantification. Migration times and peak areas were very well reproducible $(n=10, \mathrm{RSD}$ $0.08 \%$ and $2.16 \%$, respectively). No significant blank values were found. The HMSA detection limit (LOD; three times the standard deviation of the background signal) was $1.15 \mu \mathrm{m}$ $(127 \mathrm{ppb})$ and the quantification limit (LOQ; LOQ = 3 LOD) was $3.44 \mu \mathrm{m}$ (382 ppb). 
HMSA concentrations above the LOD were found in 224 of 738 samples. From these 224 samples, 157 had HMSA concentrations between the LOD and the LOQ. Even though concentrations in this range are less reliable, they were still considered in this study, since the concentrations uncertainties associated with such concentrations are regarded less problematic than setting all those HMSA concentrations to zero. Thus, in the present study, all HMSA concentrations above the LOD are reported. In atmospheric units, the LOD corresponds to mass concentrations of about $6-7 \mathrm{ng} \mathrm{m}^{-3}$ (depending on the impactor stage and the extraction protocol). Values below the LOD were, however, taken as zero. The HMSA quantification method in this study has a slightly better LOD than the method applied by Suzuki et al. (2001), who for the first time investigated particulate HMSA by ${ }^{1} \mathrm{H}$ NMR.

The amount of organic and elemental carbon (OC/EC) was quantified using a thermographic method (C-mat 5500, Ströhlein, Germany) following VDI guideline 2465, Part 2 with minor modifications. In the first step, an aliquot of an aluminium foil was heated to $650{ }^{\circ} \mathrm{C}$ in a nitrogen atmosphere. Under these conditions, organic compounds evaporated and were flushed towards a $\mathrm{CuO}$ catalyst. There they were oxidised, forming $\mathrm{CO}_{2}$ that was subsequently quantified with a NDIR detector (OC). In the next step, after cooling to at least $75^{\circ} \mathrm{C}$, the foil was again heated to $650{ }^{\circ} \mathrm{C}$ in an oxygen atmosphere oxidising $\mathrm{EC}$, which was quantified as $\mathrm{CO}_{2}$, too. Compared to other methods, this method tends to overestimate EC and to underestimate OC (Schmid et al., 2001). However, due to the melting point of aluminium $\left(660^{\circ} \mathrm{C}\right)$, the method is limited to a temperature of $650^{\circ} \mathrm{C}$, and thermo-optical methods applying the EUSAAR2 , NIOSH or IMPROVE protocols cannot be applied. For details see Spindler et al. (2012).

\subsection{Particle aqueous phase $\mathrm{pH}$}

The charge balance in our particle samples, considering main inorganic ions $\left(\mathrm{NH}_{4}^{+}, \mathrm{Na}^{+}, \mathrm{K}^{+}, \mathrm{Ca}^{2+}, \mathrm{Mg}^{2+}, \mathrm{SO}_{4}^{2-}, \mathrm{NO}_{3}^{-}\right.$, $\mathrm{Cl}^{-}$) and organic ions (oxalate, malonate, tartronate, succinate, malate and hydroxymethanesulfonate), was generally equalised and varied only within analytical errors. Contrary to recent studies from China (Cheng et al., 2011; Zhou et al., 2012), charge balances could thus not be applied to calculate particle aqueous phase $\mathrm{pH}$ in this study. They were instead determined applying measurements of the aqueous extracts' $\mathrm{pH}$ and a model that was able to calculate the particle liquid water content. The particle aqueous phase $\mathrm{pH}$ was then calculated back from the $\mathrm{pH}$ of the aqueous extracts, assuming its dilution due to the extraction protocol mentioned above. A comparable approach was applied by Li et al. (1997) and Keene and Savoie (1998).

The $\mathrm{pH}$ of the aqueous extracts was determined using a micro pH electrode (PHR 146S microelectrode, Lazar Research Laboratories, Los Angeles, USA). The particle wa- ter content was calculated using the E-AIM model (Wexler and Clegg, 2002; www.aim.env.uea.ac.uk), which has been shown to give good agreement with measured data (Engelhart et al., 2011). In former studies, E-AIM Model III was found to be the most suitable E-AIM type for our samples (Scheinhardt et al., 2013b). The average relative humidity during the measurement and the mass concentrations of the main constituents $\left(\mathrm{NH}_{4}^{+}, \mathrm{Na}^{+}, \mathrm{SO}_{4}^{2-}, \mathrm{NO}_{3}^{-}\right.$, and $\left.\mathrm{Cl}^{-}\right)$are the model input parameters. The mass concentrations of $\mathrm{H}^{+}$and $\mathrm{OH}^{-}$were adjusted to ensure the particles' charge neutrality. The formation of insoluble solids was enabled in the calculation. The model output provided the water content.

\section{Results and discussion}

\subsection{Mass concentrations and contributions to PM}

The HMSA mass concentrations determined in atmospheric samples were highly variable within the set of 224 samples with HMSA above the detection limit (out of a total of 738 samples, see Supplement). The highest observed value of $625 \mathrm{ng} \mathrm{m}^{-3}$ was determined in a sample from Augsburg on December 16, 2009 under Winter-East conditions on impactor stage 2 . Since this value was disproportionally high (more than 2.5 times higher than the second largest value), it was identified as an outlier, most likely due to a local pollution episode at that site (analytical errors were excluded by means of repetition experiments). It was therefore regarded as being not representative and is thus not considered in the following discussions. Concentrations below detection limit were set to zero for all calculations.

The data set was investigated regarding the influence of sampling location, particle diameter and the meteorological conditions on HMSA mass concentrations (Fig. 3). Although some exceptions exist, urban sites generally exhibited higher HMSA mass concentrations than rural sites (Fig. 3a; average of the urban sites: $37.9 \mathrm{ng} \mathrm{m}^{-3}$, average of the rural sites: $23.8 \mathrm{ng} \mathrm{m}^{-3}$ ). Moreover, rural lowland sites show higher HMSA mass concentrations than mountain sites. Generally, HMSA mass concentrations in central Europe seem to be slightly higher than those in Japan $\left(14.7 \mathrm{ng} \mathrm{m}^{-3}\right.$ in urban aerosols, 1998-1999; Suzuki et al., 2001). To judge on the relative contribution of HMSA to total PM, the fraction of HMSA in PM was calculated and compared for different sample types (Fig. 4). We found HMSA to be enriched by a factor of 1.23 in urban samples $(2.21 \pm 1.08 \%$ vs. 1.79 $\pm 0.80 \%$, Fig. 4 a). Even though this is not a statistically significant difference, it is consistent with the precursors of HMSA originating from anthropogenic emissions.

Regarding the impact of the particle diameter, a strong dependency was observed, the highest HMSA mass concentrations being found on impactor stage 3 (Fig. 3b). A similar size distribution was found by Suzuki et al. (2001). Since particles of that size have the longest atmospheric lifetime 

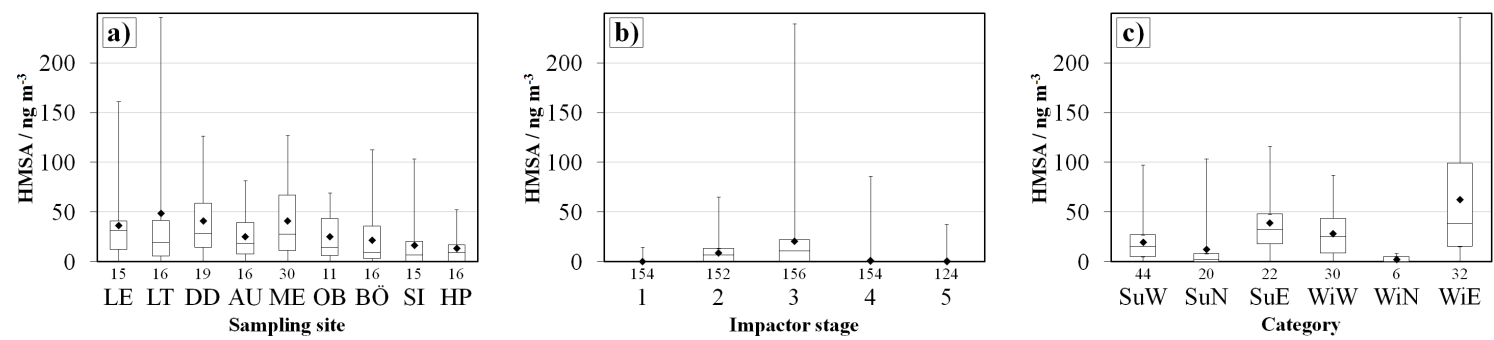

Fig. 3. (a) HMSA mass concentrations in $\mathrm{PM}_{10}$ (sum of impactor stages 1-5) as a function of the sampling site. (b) HMSA mass concentrations as a function of particle size. (c) HMSA mass concentrations in $\mathrm{PM}_{10}$ (sum of impactor stages 1-5) as a function of the meteorological category. Boxes indicate the $25 \%, 50 \%$ and $75 \%$ quartiles, whiskers indicate the minimum and maximum values. $\downarrow$ indicates the respective mean value. The number of samples is given below each column. See text for discussion.
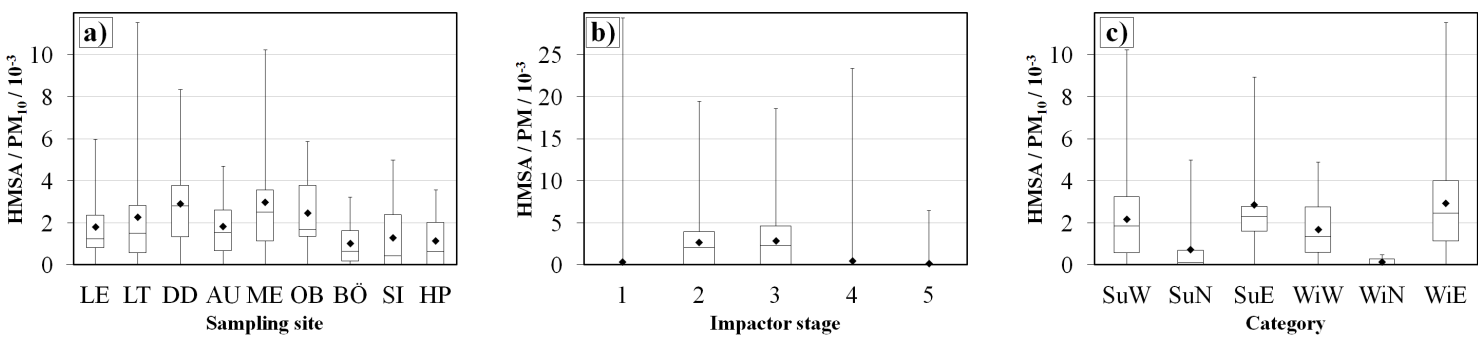

Fig. 4. (a) Fraction of HMSA in $\mathrm{PM}_{10}$ (sum of impactor stages 1-5) as a function of the sampling site. (b) Fraction of HMSA in PM as a function of the particle size. (c) Fraction of HMSA in $\mathrm{PM}_{10}$ (sum of impactor stages 1-5) as a function of the meteorological category. The symbols and numbers of samples are consistent with Fig. 3. See text for discussion.

and can therefore be transported over long distances, this observation might suggest that HMSA was formed during the aging of particles, e.g. in pollution plumes, and/or in fog or cloud processing prior to the sampling time of the aerosol particles. In fact, from its abundance in single particles with diameter $>0.7 \mu \mathrm{m}$ and its coincidence with periods of fog or high relative humidity, HMSA has been suggested to represent a tracer for fog processing (Whiteaker and Prather, 2003; Healy et al., 2012). In contrast to impactor stage 3, shortlived particles (stages 1 and 5) contain only small amounts of HMSA. The relative contribution to PM is also largest in stages 2 and 3 (Fig. 4b). However, this might be due to the low absolute amounts of HMSA on the other stages, which makes the calculation of the HMSA/PM fraction on those stages susceptible to errors.

Regarding the air mass origin, highest HMSA concentrations in total $\mathrm{PM}_{10}$ (sum of impactor stages 1-5) were observed for eastern (continental) air mass origins (Fig. 3c; West: $23.9 \mathrm{ng} \mathrm{m}^{-3}$, North: $7.7 \mathrm{ng} \mathrm{m}^{-3}$, East: $51.0 \mathrm{ng} \mathrm{m}^{-3}$ ). This reflects the high HMSA precursor concentrations (VOCs, $\mathrm{SO}_{2}$ ) in continental air masses and shows that the high anthropogenic $\mathrm{SO}_{2}$ emissions in eastern Europe not only promote the formation of main inorganic PM constituents such as sulfate, but might also enhance the formation of organic trace compounds such as HMSA. It can be presumed that similar conclusions could be drawn from the analysis of other sulfur-containing organic compounds, too.
From the fraction of HMSA in PM 10 it again appears that HMSA is enriched in some samples (Fig. 4c).

In summer, HMSA mass concentrations were lower than in winter (Fig. 3c; Summer: $23.9 \mathrm{ng} \mathrm{m}^{-3}$, Winter: $31.2 \mathrm{ng} \mathrm{m}^{-3}$ ), most likely again due to stronger anthropogenic emissions of HMSA precursors, e.g. from individual heating systems.

It should be noted that, besides emissions, the meteorological conditions in winter and during eastern air mass origin (i.e. low mixing layer height, low temperatures, decreased turbulence, few precipitation) generally favour high PM loads, too. Clearly, this applies for HMSA as well as for all the other PM constituents and might partly explain the HMSA concentration differences observed between the seasons and air mass origins.

\subsection{Correlations with other parameters}

In the previous section, absolute HMSA mass concentrations were found to show dependencies generally resembling the behaviour of total PM (i.e. highest concentrations on impactor stage 3, at urban sites, in winter and with eastern air mass origins, respectively; see Spindler et al., 2010 and 2012; Scheinhardt et al., 2013a). This is to some extent confirmed by correlating HMSA mass concentration and the total PM mass concentration (Fig. 5a). The correlation of HMSA with sulfate (Fig. 5b) is comparably strong, confirming that both HMSA and sulfate are formed from the 

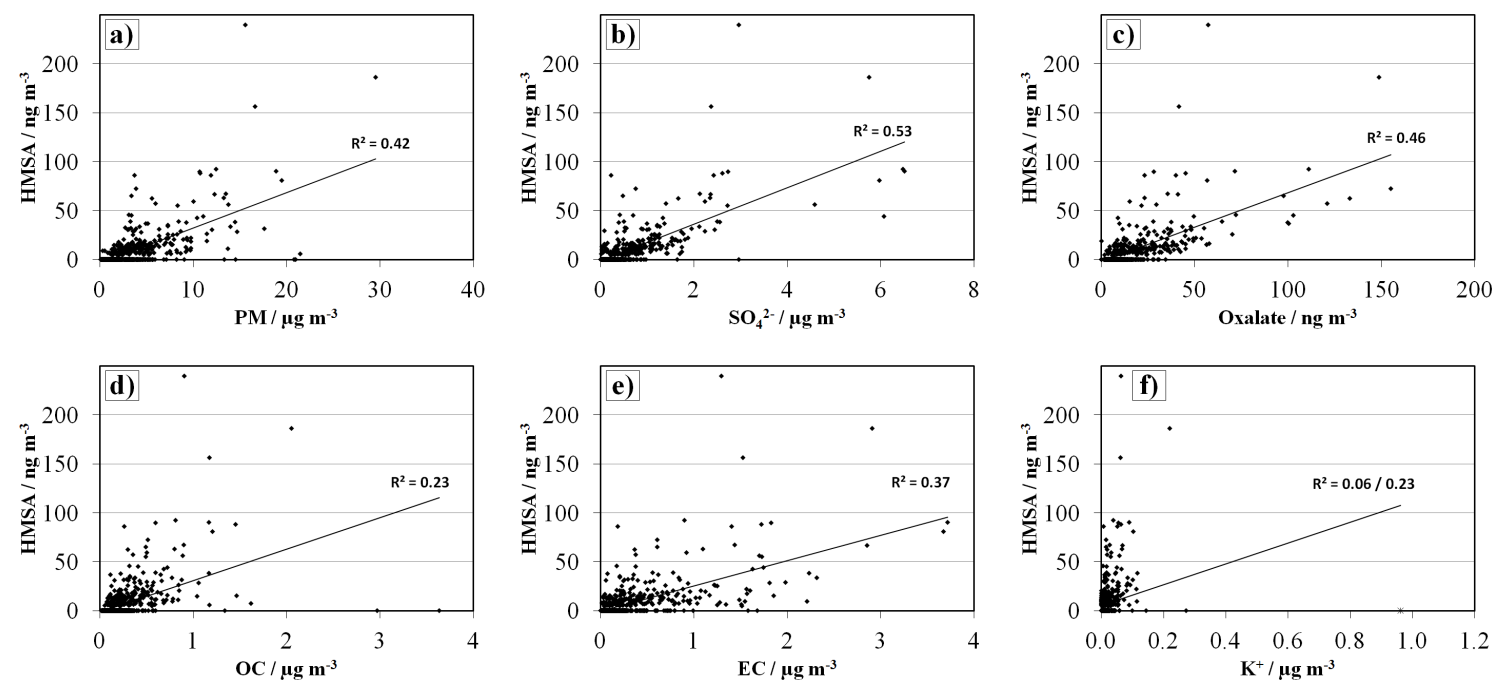

Fig. 5. Correlations of HMSA mass concentrations with (a) the respective PM mass concentration and (b-f) the mass concentrations of sulfate, oxalate, organic carbon, elemental carbon and potassium, respectively. In (f), $R^{2}$ is given with and without the consideration of an outlier $\left(0.96 \mathrm{ng} \mathrm{m}^{-3} \mathrm{~K}^{+}\right)$. The charts comprise the complete data set (738 samples). See text for discussion.
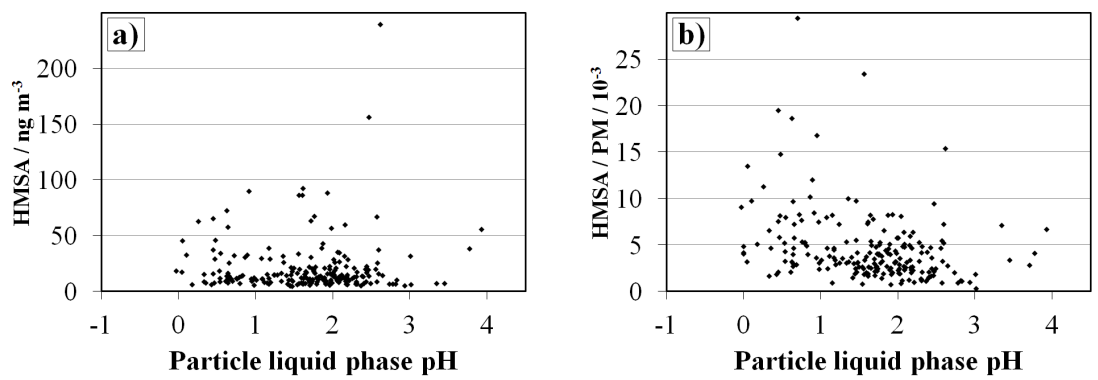

Fig. 6. (a) HMSA mass concentrations and (b) fractions of HMSA in PM as functions of the particle liquid phase pH. The charts comprise only samples with HMSA concentration above the detection limit (224 samples). See text for discussion.

same precursor $\left(\mathrm{SO}_{2}\right)$ and under comparable conditions (secondary formation in the atmospheric aqueous phase). Oxalate, which is photochemically formed from higher organic compounds, also correlates with HMSA (Fig. 5c). This also might be interpreted in a way that both substances are formed under comparable conditions (secondary formation in the atmospheric aqueous phase via photochemical multiphase oxidation processes occurring in pollution plumes), even though both substances have different precursors.

Oxalate is one of the main contributors to the sum parameter $\mathrm{OC}$, but the correlation of HMSA with OC is weak (Fig. 5d). This is probably due to the various sources of the different OC components, including, for example, direct emissions. Traffic emissions, which are characterised by high EC (diesel soot) content, seem to affect HMSA concentrations only to a minor extent (Fig. 5e). The same is true for potassium, a tracer for biomass burning (Fig. 5f). The combination of Fig. 4b-f suggests that HMSA is formed in sulfurrich aged air masses. Future discussions of HMSA formation should include direct $\mathrm{SO}_{2}$ and formaldehyde measure- ments to identify possible impacts on HMSA concentrations in more detail.

\subsection{Impact of pH}

Since the formation and degradation kinetics of HMSA is $\mathrm{pH}$-dependent, the impact of the particle aqueous phase $\mathrm{pH}$ on HMSA mass concentrations was investigated. In our study, particle aqueous phase $\mathrm{pH}$ was found to vary between about 0.5 and 2.5. These values are somewhat higher than those found in Los Angeles' particles (-2.4-0.2; Li et al., 1997) and lower than $\mathrm{pH}$ in marine particles (2.48-3.48; Keene and Savoie, 1998). The impact of $\mathrm{pH}$ on absolute HMSA mass concentrations is weak (Fig. 6a; $R^{2}$ and slope close to zero). Interestingly, the fraction of HMSA in PM shows a small dependency and decreases with increasing $\mathrm{pH}$. Although the scatter is large, this is in qualitative agreement with the decreasing stability of HMSA at increasing $\mathrm{pH}$. In our samples, an empiric relationship of $f \approx-0.16 \mathrm{pH}+0.72$ was found between $\mathrm{pH} 0$ and 4, with $\mathrm{f}$ being the percent- 
age of HMSA in $\mathrm{PM}_{10}$. It has to be noted that HMSA formation is much more effective at $\mathrm{pH}$ levels higher than the ones estimated for the samples of this study. Olson and Hoffmann, 1989, predict the formation rate to strongly increase at $\mathrm{pH}$ above approx. 4.5. It is thus plausible to assume that the formation of HMSA might have taken place at higher $\mathrm{pH}$ in cloud and fog water. Upon cloud/fog dissipation, HMSA will then be stabilised due to a much lower water content (i.e. higher apparent acidity) of the residual particles.

\section{Summary}

The present study presents data from a unique data set regarding HMSA concentrations in size-segregated ambient aerosol particles. HMSA mass concentrations were found to be highly variable. Highest concentrations were found in urban environments during winter and eastern advection on Berner impactor stage $3(\mathrm{Dp}=0.42-1.2 \mu \mathrm{m})$. The fraction of HMSA in PM generally showed similar trends. HMSA concentrations correlated with sulfate $\left(R^{2}=0.53\right)$, oxalate $\left(R^{2}=0.46\right)$ and PM $\left(R^{2}=0.42\right)$ mass concentrations. Correlations with EC $\left(R^{2}=0.37\right)$, OC $\left(R^{2}=0.23\right)$ and potassium $\left(R^{2}=0.23 / 0.06\right)$ were also observed, but to a lesser extent. The fraction of HMSA in PM seems to be slightly influenced by $\mathrm{pH}$, possibly due to its $\mathrm{pH}$-dependent stability. Overall, the results are consistent with well-known aqueous phase formation of HMSA in polluted air masses from anthropogenic precursors $\mathrm{SO}_{2}$ and formaldehyde.

Acknowledgements. This study has been supported by the German Federal Ministry of Education and Research under grant no. 01LR0802 (REGKLAM) and by the German Federal Environment Ministry under grant no. F\&E 370343200 (GUAN). We thank all our project partners in GUAN and REGKLAM. We would also like to thank our technical staff - A. Dietze, S. Fuchs, A. Grüner, R. Rabe and A. Thomas - as well as two undergraduate students, A. Rau (Universität Leipzig) and E. Charlesworth (Seattle University), for whom DAAD RISE support is gratefully acknowledged. Input of two anonymous reviewers to our paper is much appreciated as well.

Edited by: S. A. Nizkorodov

\section{References}

Birmili, W., Weinhold, K., Nordmann, S., Wiedensohler, A., Spindler, G., Müller, K., Herrmann, H., Gnauk, T., Pitz, M., Cyrys, J., Flentje, H., Nickel, C., Kuhlbusch, T. A. J., Löschau, G., Haase, D., Meinhardt, F., Schwerin, A., Ries, L., and Wirtz, K.: Atmospheric aerosol measurements in the German Ultrafine Aerosol Network (GUAN), Gefahrst. Reinhalt. L., 69, 137-145, 2009.

Cheng, S. H., Yang, L. X., Zhou, X. H., Xue, L. K., Gao, X. M., Zhou, Y., and Wang, W. X.: Size-fractionated water-soluble ions, situ $\mathrm{pH}$ and water content in aerosol on hazy days and the influences on visibility impairment in Jinan, China, Atmos. Environ., 45, 4631-4640, 2011.

Draxler, R. R. and Hess, G. D.: An overview of the HYSPLIT_4 modelling system for trajectories, dispersion and deposition, Aust. Meteorol. Mag., 47, 295-308, 1998.

Engelhart, G. J., Hildebrandt, L., Kostenidou, E., Mihalopoulos, N., Donahue, N. M., and Pandis, S. N.: Water content of aged aerosol, Atmos. Chem. Phys., 11, 911-920, doi:10.5194/acp-11911-2011, 2011

Healy, R. M., Sciare, J., Poulain, L., Kamili, K., Merkel, M., Müller, T., Wiedensohler, A., Eckhardt, S., Stohl, A., Sarda-Estève, R., McGillicuddy, E., O'Connor, I. P., Sodeau, J. R., and Wenger, J. C.: Sources and mixing state of size-resolved elemental carbon particles in a European megacity: Paris, Atmos. Chem. Phys., 12, 1681-1700, doi:10.5194/acp-12-1681-2012, 2012.

Hoigné, J., Bader, H., Haag, W. R., and Staehelin, J.: Rate constants of reactions of ozone with organic and inorganic compounds in water - III. Inorganic compounds and radicals, Water Res., 19, 993-1004, 1985.

Katagiri, Y., Sawaki, N., Arai, Y., Okochi, H., and Igawa, M.: Enhanced dissolution of $\mathrm{SO}_{2}$ into dewwater by forming hydroxyalkanesulfonate, Chem. Lett., 3, 197-198, 1996.

Keene, W. C. and Savoie, D. L.: The $\mathrm{pH}$ of deliquesced sea-salt aerosol in polluted marine air, Geophys. Res. Lett., 25, 21812184, 1998.

Kramberger-Kaplan, H. V.: Carbonsäuren und Dicarbonsäuren in atmosphärischen Mehrphasenprozessen, Ph.D. Thesis, Technische Universität Darmstadt, Darmstadt, Germany, 2003.

Li, S. M., Macdonald, A. M., Strapp, J. W., Lee, Y. N., and Zhou, X. L.: Chemical and physical characterizations of atmospheric aerosols over Southern California, J. Geophys. Res.Atmos., 102, 21341-21353, 1997.

Martin, L. R., Easton, M. P., Foster, J. W., and Hill, M. W.: Oxidation of hydroxymethanesulfonic acid by Fenton's reagent, Atmos. Environ., 23, 563-568, 1989.

McArdle, J. V. and Hoffmann, M. R.: Kinetics and mechanism of the oxidation of aquated sulfur dioxide by hydrogen peroxide at low pH, J. Phys. Chem., 87, 5425-5429, 1983.

Munger, J. W., Jacob, D. J., and Hoffmann, M. R.: The Occurrence of bisulfite-aldehyde addition products in fog-and cloudwater, $\mathrm{J}$. Atmos. Chem., 1, 335-350, 1984

Munger, J. W., Tiller, C., and Hoffmann, M. R.: Identification of hydroxymethanesulfonate in fog water, Science, 231, 247-249, 1986.

Olson, T. M. and Hoffmann, M. R.: Hydroxyalkylsulfonate formation: its role as a S(IV) reservoir in atmospheric water droplets, Atmos. Environ., 23, 985-997, 1989.

Ojo, J. F., Otoikhian, A., Olojo, R., and Simoyi, R. H.: OxyhalogenSulfur chemistry: nonlinear oxidation kinetics of hydroxymethanesulfonic acid by acidic iodate, J. Phys. Chem. A, 108, 2457-2463, 2004

Richards, L. W., Anderson, J. A., Blumenthal, D. L., McDonald, J. A., Kok, G. L., and Lazrus, A. L.: Hydrogen peroxide and sulfur (IV) in Los Angeles cloud water, Atmos. Environ., 17, 911-914, 1983.

Scheinhardt, S., Spindler, G., Leise, S., Müller, K., Iinuma, Y., Zimmermann, F., Matschullat, J., and Herrmann, H.: Comprehensive chemical characterisation of size-segregated $\mathrm{PM}_{10}$ in Dresden 
and estimation of changes due to global warming, Atmos. Environ., 75, 365-373, 2013a.

Scheinhardt, S., Müller, K., Spindler, G., and Herrmann, H.: Complexation of trace metals in size-segregated aerosol particles at nine sites in Germany, Atmos. Environ., 74, 102-109, 2013b.

Schmid, H., Laskus, L., Abraham, H. J., Baltensperger, U., Lavanchy, V., Bizjak, M., Burba, P., Cachier, H., Crow, D., Chow, J., Gnauk, T., Even, A., ten Brink, H. M., Giesen, K. P., Hitzenberger, R., Hueglin, C., Maenhaut, W., Pio, C., Carvalho, A., Putaud, J. P., Toom-Sauntry, D., and Puxbaum, H.: Results of the "carbon conference" international aerosol carbon round robin test stage I, Atmos. Environ., 35, 2111-2121, 2001.

Sorensen, P. E. and Andersen, V. S.: The formaldehyde-hydrogen sulphite system in alkaline aqueous solution. Kinetics, mechanisms, and equilibria, Acta Chem. Scand., 24, 1301-1306, 1970.

Spindler, G., Brüggemann, E., Gnauk, T., Grüner, A., Müller, K., and Herrmann, H.: A four-year size-segregated characterization study of particles $\mathrm{PM}_{10}, \mathrm{PM}_{2.5}$ and $\mathrm{PM}_{1}$ depending on air mass origin at Melpitz, Atmos. Environ., 44, 164-173, 2010.

Spindler, G., Gnauk, T., Grüner, A., Iinuma, Y., Müller, K., Scheinhardt, S., and Herrmann, H.: Size-segregated characterization of $\mathrm{PM}_{10}$ at the EMEP site Melpitz (Germany) using a five-stage impactor: a six year study, J. Atmos. Chem., 69, 127-157, 2012.

Spindler, G., Grüner, A., Müller, K., Schlimper, S., and Herrmann, H.: Long-term size-segregated particle $\left(\mathrm{PM}_{10}, \mathrm{PM}_{2.5}\right.$, $\mathrm{PM}_{1}$ ) characterization study at Melpitz - influence of air mass inflow, weather conditions and season, J. Atmos. Chem., 70, 165$195,2013$.
Suzuki, Y., Kawakami, M., and Akasaka, K.: 1H NMR application for characterising water-soluble organic compounds in urban atmospheric particles, Environ. Sci. Technol., 35, 3656-2664, 2001.

Takeuchi, M., Okochi, H., and Jgawa, M.: Dominant factors of major and minor components and formation of hydroxyalkanesulfonate in urban dew-water, Water Air Soil Poll., 130, 613-618, 2001.

Wexler, A. S. and Clegg, S. L.: Atmospheric aerosol models for systems including the ions $\mathrm{H}^{+}, \mathrm{NH}_{4}^{+}, \mathrm{Na}^{+}, \mathrm{SO}_{4}^{2-}, \mathrm{NO}_{3}^{-}$, $\mathrm{Cl}^{-}, \mathrm{Br}^{-}$, and $\mathrm{H}_{2} \mathrm{O}$, J. Geophys. Res. Atmos., 107, 4207, doi:10.1029/2001JD000451, 2002.

Whiteaker, J. R. and Prather, K. A.: Hydroxymethanesulfonate as a tracer for fog processing of individual aerosol particles, Atmos. Environ., 37, 1033-1043, 2003.

Voisin, D., Legrand, M., and Chaumerliac, N.: Scavenging of acidic gases $\left(\mathrm{HCOOH}, \mathrm{CH}_{3} \mathrm{COOH}, \mathrm{HNO}_{3}, \mathrm{HCI}\right.$, and $\left.\mathrm{SO}_{2}\right)$ and ammonia in mixed liquid-solid water clouds at the Puy de Dôme mountain (France), J. Geophys. Res., 105, 6817-6835, 2000.

Zhou, Y., Xue, L. K., Wang, T., Gao, X. M., Wang, Z., Wang, X. F., Zhang, J. M., Zhang, Q. Z., and Wang, W. X.: Characterization of aerosol acidity at a high mountain site in Central Eastern China, Atmos. Environ., 51, 11-20, 2012. 